\title{
Kentsel Arkeolojik Sit Alanlarında Koruma Yaklaşımı: Denizli, Hisar (Attouda) Örneğiं
}

\author{
The Conservation Approach in Urban Archaeological Sites: The Case of Hisar \\ (Attouda), Denizli
}

\section{Ayşe Özdemir* ${ }^{*}$, İcan Şimşek ${ }^{* * *}$}

\section{Öz}

Doğal ve kültürel miras değerlerine sahip korunan alanların geleceğe taşınması için ne gibi önlemler alınması gerektiği tartışılması gereken konulardan biridir. Bu çalışmanın amacı, arkeolojik, mimari ve tarihî ögelerin birlikteliğine dayanan arkeolojik sit alanlarının güncel yaşam ile bütünleştirilmesi yoluyla kültürel sürekliliğinin devam ettirilmesine yönelik koruma yaklaşımı önerilmesidir. Araştırma kapsamında birinci derece arkeolojik ve kentsel sit alanı statüsündeki Hisar (Attouda) yerleşimi örneklem alan olarak seçilmiştir.

Araştırma yöntemi kapsamında Hisar (Attouda) yerleşiminin koruma geçmişine ilişkin koruma kurulu kararları, imar planları ve raporları incelenmiş, GZFT (SWOT) analizi ile doğal ve kültürel miras değerlerinin korunmasına ve yaşatılmasına yönelik güçlü ve zayıf yönler ile fırsat ve tehditler saptanmıştır. Bu bilgiler doğrultusunda, geçmişten günümüze ulaşan doğal ve kültürel miras değerlerinden oluşan kentsel arkeolojik sit alanı özelliğindeki Hisar (Attouda) yerleşim dokusu, bütünleşik koruma yaklaşımı kapsamında ele alınarak, kültürel sürdürülebilirliğin sağlanması için bugün ve geleceğe yönelik koruma önerileri getirilmiştir.

\section{Anahtar Kelimeler}

Hisar, Attouda, kültürel miras, doğal miras, kentsel arkeolojik sit, koruma

\begin{abstract}
In order to carry protected areas with natural and cultural heritage values into the future, one of the issues that needs to be discussed is what kind of measures need to be taken. The aim of this study is to propose a conservation approach to maintain cultural continuity with the integration of archaeological sites (which is based on the unity of archaeological, architectural and historical elements), into contemporary life. Within the scope of the research, the Hisar (Attouda) settlement, which has the status of a first degree archaeological and urban site, was selected as the sample area.

Within the scope of the research method, the conservation committee decisions, zoning plans and reports regarding the conservation history of the Hisar (Attouda) settlement were examined, and the strengths, weaknesses, opportunities
\end{abstract}

* Bu makale Pamukkale Üniversitesi Fen Bilimleri Enstitüsü Şehir ve Bölge Planlama Anabilim Dalı'nda Doç. Dr. Ayşe Özdemir'in danışmanlığında İlcan Şimşek tarafindan hazırlanan “Kentsel Arkeolojik Sit Alanlarında Koruma-Canlandırma Önerileri: Hisar (Attouda) Örneği” başlıklı yüksek lisans tez çalışması temel alınarak kurgulanmıştır.

** Sorumlu Yazar: Ayşe Özdemir (Doç. Dr.), Pamukkale Üniversitesi, Mimarlık ve Tasarım Fakültesi, Peyzaj Mimarlığı Bölümü, Denizli, Türkiye. E-posta: ayseozdemir@pau.edu.tr ORCID: 0000-0002-0182-6766

*** İlcan Şimşek (Peyzaj Mimarı, Şehir ve Bölge Planlama Bilim Uzmanı), Fuks \& Wagner GmbH, Berlin, Almanya. E-posta: ilcansimsek@gmail.com ORCID: 0000-0003-2409-880X

Atıf: Ozdemir, Ayse ve Simsek, Ilcan. "Kentsel Arkeolojik Sit Alanlarında Koruma Yaklaşımı: Denizli, Hisar (Attouda) Örneği." Art-Sanat, 15(2021): 229-248. https://doi.org/10.26650/artsanat.2021.15.0010 
and threats for the protection and preservation of natural and cultural heritage values were determined with a SWOT analysis. In line with this information, the Hisar (Attouda) settlement texture, which is an urban archaeological site consisting of natural and cultural heritage values from the past to the present, was dealt within the scope of an integrated conservation approach, and preservation proposals for today and for the future were made in order to ensure cultural sustainability.

Keywords

Hisar, Attouda, Cultural heritage, Natural heritage, Urban archaeological site, Conservation

\section{Extended Summary}

Multi-layered settlements bearing the traces of different civilizations from different historical periods face the risk of extinction due to physical, social and economic problems. At this point, what can be done in terms of the conservation and sustainability of the culture, history, geography, socio-economic situation, traditional architectural texture, and natural and cultural heritage values of the settlements should be discussed. In this study, the main focus was on the cultural and natural heritage values of protected areas as urban archaeological sites and what can be done to carry these values into the future. In this context, the ancient city of Attouda in the Sarayköy District of Denizli province and the Hisar settlement, which was established on the ancient city at a later period, were evaluated as study areas. The research, which is based on sustainably preserving the natural and cultural values of the Hisar (Attouda), an urban archeological site, and transferring them to future generations, was carried out in three stages.

In the first stage, written and visual sources and archaeological studies about the research area were examined, and face-to-face interviews were held with local people, experts on the subject and scientists who have carried out studies in this field of research. Concurrently, an institutional research was carried out to obtain visual and written documents on the subject of the conservation process in the field of research. The natural and cultural values of the area were determined and maps regarding the current situation were created with AutoCAD, Photoshop and Netcad programs.

In the second stage, the decisions taken and the documents about the area to be declared as a protected area by the conservation committee and the works made for conservation in the following processes within the scope of analysis were primarily examined in the conservation history analysis of the research area and deficiencies and problems were determined. The strengths and weaknesses of the area were determined with the SWOT analysis aimed at preserving the area sustainably in line with the natural and cultural values of the research area, and opportunities and threats arising from the external environment were identified.

Conservation and revitalization suggestions were made at a regional and settlement level based on the integrated conservation approach by evaluating the information obtained regarding the current situation of the area in order to revitalize the settlement 
by revealing the natural and cultural values of the area, to preserve and transfer it to future generations with all the studies carried out and the data obtained in the third stage. In the proposals, the values bearing the characteristics of the past were taken into consideration in a way that includes both the present and the future, and it was taken into consideration that surface exploration and archaeological excavation areas and the existing settlement should be managed in an interactive and holistic way without affecting each other.

Considering the natural and cultural landscape characteristics of the Hisar (Attouda) settlement, located on the route of ancient cities (e.g. Aphrodisias, Trapezopolis, Laodikeia, Hierapolis, Tripolis), its region and the historical and socio-cultural settlements that stand out along the route and their proximity to each other, the use of a cultural route is envisaged as a conservation and revitalization proposal on a regional scale. In addition, for this purpose, the necessity of planning-implementation studies by the relevant public institutions and organizations was put forward in order to increase the quality of infrastructure and space, to make improvements in areas requiring urgent intervention on the determined route, to conserve and develop the natural, historical and cultural sites and structures considered as an element of the route, to increase visibility and accessibility, to re-use the buildings by giving appropriate functions within the scope of cultural tourism by abiding to the principles of the use and preservation.

For the Hisar (Attouda) settlement, which is an urban archaeological site, conservation and revitalization proposals at the settlement level were discussed as (a) recommendations on conservation-oriented intervention areas in the context of cultural values, (b) recommendations on natural values, (c) conservation recommendations for surface exploration and excavation areas.

Both traditional architectural texture conservation works and excavations should be planned in a way so that they do not affect each other but interact with each other and an approach to the conservation and sustainability of its cultural heritage and settlement texture should be adopted. All kinds of work to be done in the surface exploration and excavation area and in the urban site area should be carried out within the legal framework based on conservation principles. The excavations within the urban site boundary and the protection and exhibition of the archaeological findings afterwards and the restoration, renewal and rehabilitation works within the urban site should be planned and implemented together. Immovable cultural assets uncovered after excavations should be preserved in situ, and portable cultural assets should be preserved by being exhibited in or around the appropriate museum.

As a result, evaluating the readability, preservation and enhancement of the unique natural and cultural features of the area, the recognition of the field and its contribu- 
tion to regional development on the basis of preservation and stimulation that can be accurate and effective will allow the sustainability of the field from the past to the future on the axis of a rational and holistic approach. In this context, it is believed that the conservation and revitalization suggestions put forward on the basis of the integrated conservation approach with this research will contribute to the planning-design and implementation processes in order to preserve the historical past of the cultural heritage area of Hisar (Attouda), an area which has survived from the past to the present and has been shaped by changes and transformations in the historical continuity, and to protect and transfer it to the future generations. 


\section{Giriş}

Tarihsel süreç içerisinde farklı medeniyetlerin izlerini taşıyan doğal ve kültürel değerlerinin birlikteliğine dayanan çok katmanlı kırsal ve kentsel yerleşimler, yaşadıkları dönemin sosyal, ekonomik ve kültürel özelliklerini yansıtırlar. Özellikle kırsal alanlarda bulundukları bölgenin fiziksel şartlarını, doğa ile iç içe, arazi formuna uygun, doğal kaynaklara ve etki alanlarına, iklim özelliklerini, kültürünü, ait oldukları dönemin yaşam izlerini yansıtan, özgün dokulara sahip kırsal yerleşmeler ${ }^{1}$ kendine $^{2}$ özgü çok yönlü koruma yaklaşımları gerektirmektedir. Bu yerleşmeler geçmişin izlerini taşıyan dinamik, değişken, evrimleşen ve bulundukları çevreyle bütünleşmiş arkeolojik peyzajlar niteliği ile UNESCO, HABITAT, ICOMOS ve Avrupa Konseyi gibi küresel düzlemdeki organizasyonlar tarafından yayınlanan sözleşmeler, tüzükler, tavsiye ya da ilke kararlarında insanlık tarihinin "ortak belleği”" olarak değerlendirilmektedir². Ancak günümüzde tarihsel geçmişe dayanan özgün karaktere sahip kırsal yerleşmelerin, göç, doğal afet ya da fiziksel müdahaleler ile tahribata uğradığ dolayısıyla barındırdıkları somut ve somut olmayan miras değerlerinin de risk altında olduğu söylenebilir. Kırsal yerleşmelerin doğal ve kültürel miras değerlerinin korunması, toplumun geçmişteki yaşanmışlıkları “anı değeri” olarak hatırlanırken, diğer yandan gelecek nesillere geçmiş kültürel kimliğin/benliğin aktarılması yoluyla kültürel sürekliliğin sağlanması bakımında önemlidir. Bu noktada Amsterdam Bildirgesi (1975)'nde ifade edildiği gibi bütünleşik koruma yaklaşımı kapsamında korunan yerleşim alanların sadece fiziksel ve tarihi değerleriyle değil, bütünleşik koruma yaklaşımı doğrultusunda ekonomik ve sosyal nitelikleriyle de korunarak güncel kentsel dinamikler içinde yaşatılması sağlanmalıdır. ${ }^{3}$

$\mathrm{Bu}$ araştırmanın amacı, çok katmanlı yerleşim karakteri gösteren Hisar (Attouda) yerleşim dokusunun, doğal ve kültürel miras değerlerinin tespit edilerek bu değerlerin korunması ve gelecek nesillere aktarılması amacıyla bütünleşik koruma yaklaşımı temelinde geleceğe yönelik koruma önerileri getirilmesidir.

Araştırmanın konusu, Denizli ili Sarayköy ilçesi, Hisar mahallesinde bulunan Hisar (Attouda) yerleşimidir (G. 1). Yerleşim alanı, Lykos Vadisinin batısındaki Salbakos Dağı'nın doğu yamacında, kuzey, güney ve doğu kısımları dik yamaçlarla çevrili bir sırt üzerinde kurulmuştur. Aphrodisias ile Laodikeia, Hierapolis ve Tripolis antik kentlerini birbirine bağlayan antik yol üzerinde yer almaktadır.

1 “Kırsal Kalkınma Özel İhtisas Komisyonu Raporu, Sekizinci Beş Yıllık Kalkınma Planı”, Devlet Planlama Teşkilatı, Ankara, 2000, 26-27, erişim 13 Mart 2019, https://sbb.gov.tr/wp-content/uploads/2018/11/08_KirsalKalkinma.pdf ; Zehra Eminağaoğlu ve Sonay Çevik, "Kırsal Yerleşmelere İlişkin Tasarım Politikaları ve Araçlar,” Gazi Üniversitesi Mühendislik Mimarlık Fakültesi Dergisi 22/1 (2007), 157-162.

2 Elmas Erdoğan, "Perge Arkeolojik Sit Alanı, Peyzaj Özellikleri ve Koruma Sorunları,” Bartın Orman Fakültesi Dergisi 8/10 (2006), 36; Koray Özcan ve M. Serhat Yenice, “Arkeolojik Mirasın Sürdürülebilirliği: KorumaGeliştirme Stratejileri İçin Bir Yöntem Önerisi,” Uluslararası İnsan Bilimleri Dergisi 5/1 (2008), 2.

3 Zeynep Ahunbay, Tarihi Çevre Koruma ve Restorasyon. İstanbul: YEM Yayınları, 2007, 16-18. 


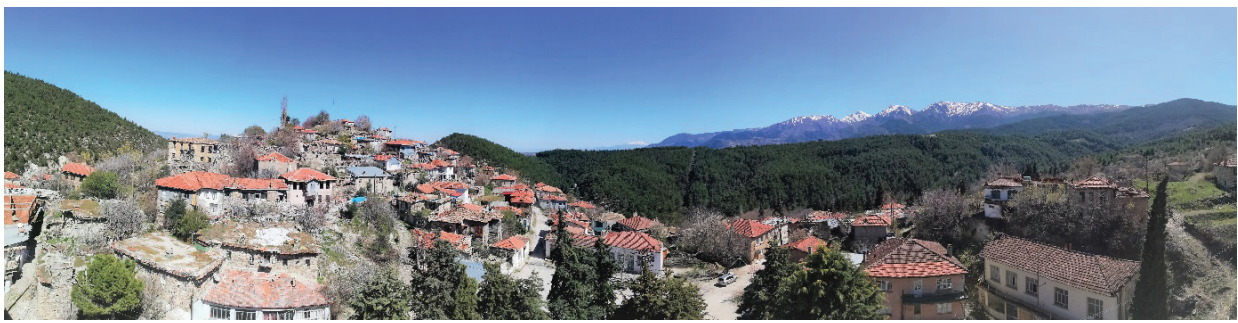

G. 1. Hisar Yerleşiminin Genel Görünüşü (Şimşek, 2019)

Helenistik ve Roma Dönemi’nden günümüze ulaşan, yaşadıkları devrin sosyal, ekonomik ve kültürel özelliklerini yansıtan kültür varlığının yer aldığı Attouda Antik Kenti I. derece arkeolojik sit alanıdır'. Hisar (Attouda) yerleşiminin somut kültürel miras değerleri, antik döneme tarihlenen somut kültürel arkeolojik kalıtlar ${ }^{5}$ ve Roma dönemine tarihlenen dinsel ve anıtsal yapılara ilişkin mimari elemanlardan oluşan mimari kalıntılardır. ${ }^{6}$ Antik kentin üzerinde bulunan Hisar yerleşiminde Roma-Bizans döneminden Osmanlı dönemine kadar uzanan zaman aralığında tarihlenen kendi içinde farklı örneklerin olduğu tarihi evler ${ }^{7}$ bulunmaktadır. Evlerin arasında yer yer korunmuş Osmanlı dönemi taş döşemeli yollar bulunmaktadır. Yerleşim etrafındaki vadiler, dağlık alanlar ve orman örtüsü karışık geniş ve iğne yapraklı ağaç ve çalılardan oluşmaktadır. Araştırma alanı ve çevresinin bitki ve hayvan çeşitliliği zenginlik göstermektedir ${ }^{8}$. Hisar yerleşimi mimari dokusu, estetik değerleri ve geçmiş dönemlere ait hayat biçimlerini gelecek nesillere aktarması, doğal ve kültürel değerleri bir arada bulundurması açısından kentsel sit alanı özelliği taşımaktadır.

Günümüzde Helen, Roma, Bizans ve Türk dönemleri yerleşim miraslarının birlikteliği olarak çok katmanlı yerleşim karakteri gösteren Hisar (Attouda) yerleşim dokusu Aydın Kültür Varlıklarını Koruma Bölge Kurulu'nun 25.10.2013 tarih 2098 nolu kararı ile kentsel arkeolojik sit statüsü ile koruma altına alınmıştır. Bu durumun getirdiği yapılaşma kısıtlılı̆̆ ler, konutlardaki fiziksel eskime-köhneme gibi fiziksel sorunlar, altyapı sorunları ile

4 İzmir II. Numaralı Kültür ve Tabiat Varlıklarını Koruma Kurulunun 21.09.1988 tarih ve 398 sayılı kararı ile sit sınırı belirlenmiştir.

5 Celal Şimşek, "Attouda Nekropolü," Birinci Uluslararası Aşağı Büyük Menderes Havzası Tarih, Arkeoloji ve Sanat Tarihi Sempozyumu, Söke, 15-16 Kasım 2001, ed. Adil Adnan Öztürk (Aydın: Adnan Menderes Üniversitesi, 2002), 229-245.

6 Bilal Söğüt, “Attouda (Hisar) Antik Kenti," Cedrus Akdeniz Uygarlıkları Araştırma Dergisi 5 (2017), 243246.

7 Toplam 143 adet tescilli kültür varlığı bulunmaktadır.

8 Raşit Urhan vd., "Babadağ (Denizli) İlçesinin Memeli Hayvanları," I. Babadağ Sempozyumu Tarihte ve Günümüzde Babadağ Bildiri Metinleri (Denizli: Pamukkale Üniversitesi, 1999), 179-180; Sefa Gez ve Solmaz Şimşek, "Babadağ'ın Tıbbi Bitkileri”" I. Babadağ Sempozyumu Tarihte ve Günümüzde Babadağ Bildiri Metinleri (Denizli: Pamukkale Üniversitesi, 1999), 128-135; Ali Çelik, Mehmet Çiçek ve Muhammet Uşak, "Denizli İli ve Çevresinde Yayılış Gösteren Bazı Türlerin Etnobotanik Özellikleri," I. Babadağ Sempozyumu Tarihte ve Günümüzde Babadağ Bildiri Metinleri (Denizli: Pamukkale Üniversitesi, 1999), 136-154. 
iş olanakları bağlamında ekonomik sorunlar bölgedeki yerleşimi etkilemektedir. $\mathrm{Bu}$ süreçte, bir kısmı yerleşimcilerin iki kilometre kuzeyde kurulan yeni yerleşim alanına taşındığı, birçoğunun ise iş olanaklarından dolayı Denizli'ye taşındığı anlaşılmaktadır. Ancak, halkın her ne kadar yeni yerleşim alanına veya kent merkezine taşınmakla birlikte Hisar (Attouda) kimliğine olan aidiyetin devam ettiği ve Hisar (Attouda) yerleşimindeki konutları, kahvehane, cami ve bahçelerini dönemsel (bayramlar veya yaz dönemi gibi) olarak kullanmaktan vazgeçmediği görülmektedir.

\section{Yöntem}

Araştırmada arkeolojik kentsel sit niteliğindeki koruma alanının sahip olduğu kültürel ve doğal değerlerinin belirlenmesi sonucu alan bütünleşik koruma yaklaşımı temelinde değerlendirilmiştir. Bu süreçte geçmiş̧in özelliklerini taşıyan değerlerin, bugünü ve geleceği de kapsayacak şekilde ele alınarak arkeolojik alanlar ile mevcut yerleşimin birbirini etkilemeden ancak birbiriyle etkileşimli, bütüncül değerlendirilmesi koruma kararları ve ilkeleri esas alınarak yapılmıştır.

Bu kapsamda araştırma üç aşamada gerçekleştirilmiştir. Birinci aşamada araştırma alanına yönelik yazılı ve görsel kaynaklar ile arkeolojik çalışmalar incelenmiş, konu ile ilgili uzman, araştırma alanı ile ilgili çalışmaları olan bilim insanları ve yerel halk ile yüz yüze görüşmeler gerçekleştirilmiştir. Aynı zamanda araştırma alanında koruma sürecine ilişkin görsel ve yazılı belgelerin teminine yönelik kurum araştırması yapılmıştır. Analiz aşaması olan ikinci aşamada, özellikle kurum araştırmasından elde edilen koruma kurulu kararları, imar planları ve raporları ile diğer hukuki bilgi-belgeler kapsamında öncelikli olarak koruma geçmişi analiz edilmiştir. Bununla birlikte korumaya yönelik yapılmış çalışmalar GZFT analizi ile irdelenerek, koruma sürecine ilişkin eksiklik/riskler ve sorunlar ile gelişme potansiyelleri ve fursatlar belirlenmiştir. Üçüncü aşamada ise tarihi süreç içerisinde şekillenen yerleşim dokusunun özgünlüğünün bütüncül olarak korunarak yaşatılması ve gelecek kuşaklara aktarılması için mevcut durumuna ilişkin belirlenen bilgiler değerlendirilerek bölgesel ölçekte ve yerleşim ölçeğinde koruma önerileri getirilmiştir.

\section{Koruma Odaklı Analizler}

Koruma odaklı analizler, Hisar (Attouda) yerleşiminin kentsel arkeolojik sit statüsü bağlamında ilgili Koruma Kurulu kararları, imar planları ve raporlarından oluşan belgelere dayalı olarak koruma sürecinin tespiti ile güçlü-zayıf yönler ile firsat ve tehditlere ilişkin GZFT Analizi değerlendirmeleri olarak ele alınmıştır.

\section{Koruma Süreci}

Attouda Antik Kenti, İzmir II. Numaralı Kültür ve Tabiat Varlıklarını Koruma Kurulunun 21.09.1988 tarih ve 398 sayılı kararı ile 1. Derece Arkeolojik Sit Alanı s1- 
nırları belirlenerek tescillenmiştir. Aydın Kültür ve Tabiat Varlıklarını Koruma Bölge Kurulu'nun 24.12.2009 tarih ve 2511 say1l kararı ile tescil edilen, Koruma Bölge Kurulu Müdürlüğü uzmanlarının 21.12.2009 tarihli raporu ile 2863 sayılı Kültür ve Tabiat Varlıklarını Koruma Kanunu kapsamında korunması gerekli kültür varlığı özelliği olmasıyla Hisar'ın tescilinin uygun olduğuna karar verilmiştir. Bu kapsamda kentsel arkeolojik sit sınırı içerisinde Aydın Kültür ve Tabiat Varlıklarını Koruma Bölge Kurulunun 24.12.2009 tarih ve 2511 sayıl1 kararı ile liste tescili olarak 143 adet (141 adet sivil mimarlık örneği ile 2 adet anıtsal yapı) taşınmaz kültür varlığı tescillenmiştir. Hisar yerleşimi ise Aydın Kültür Varlıklarını Koruma Bölge Kurulu'nun 25.10.2013 tarih ve 2098 nolu kararı ile kentsel arkeolojik sit sınırı belirlenmiştir. T.C. Çevre ve Şehircilik Bakanlığı tarafından 04.08.2016'da onaylanan Aydın-Muğla-Denizli Planlama Bölgesi 1/100.000 ölçekli Çevre Düzeni Planı hükümlerine göre; 2863 sayılı "Kültür ve Tabiat Varlıklarını Koruma Kanunu" uyarınca belirlenen ve belirlenecek olan sit alanları ile kültür ve tabiat varlıklarının ilgili yasalar ve yönetmelikler uyarınca korunması gerekliliği plan hükümlerinde yer almaktadır. Ancak Hisar (Attouda) yerleşimi Çevre Düzeni Planı hükümleri arasında yer almamakta olup plan üzerinde ören yeri olarak belirtilmektedir.

Bununla birlikte literatürde araştırma alanı ile ilgili olarak farklı disiplinlerde yapılmış çalışmalar bulunmaktadır. Bu bilgiler kültürel miras değerlerinin korunmasına envanter oluşturması açısından önemlidir. 1890 yılında Ramsay ${ }^{9}$, Hisar ve çevresi ile ilgili coğrafi bilgiler aktarmıştır. Anderson $(1897)^{10}$, Buckler ve Calder (1939) ${ }^{11}$, Sheppard (1981) $)^{12}$ ve Malay (1994) ${ }^{13}$ Hisar (Attouda) yerleşiminde bulunan yazıtlar ile ilgili farklı zamanlarda değerlendirmeler yapmışlardır. Şimşek 1999 ve 2002 yıllarında yapmış olduğu araştırmalarda Attouda Antik Kentinde yapılan yüzey araştırmaları, kültür varlıkları ve tarihine ilişkin bilgiler üzerinde durmuştur ${ }^{14}$. Şimşek ve Okunak 2002 yılındaki çalışmalarında antik kentin taşınabilir kültür varlıklarından seramikler ile ilgili ayrıntılı bilgi aktarmışlardır' ${ }^{15}$. Söğüt tarafından 2006, 2013 ve 2017 yıllarında yapılmış olan çalışmalarda Attouda Antik Kentine ait antik dönemden bugüne kalan eserler ve sosyo-kültürel yapısına ilişkin bilgiler verilerek, bu yerleşimin farkındalığ1-

9 William Mitchell Ramsay, The Historical Geography of Asia Minor (London: Cambridge University Press, 1890), 403-404.

10 John George Clark Anderson, “A Summer in Phrygia:1," The Journal of Hellenic Studies 18 (1898), 398-400.

11 William Hepburn Buckler ve William Moir Calder, Monuments and Documents from Phrygia and Caria. (Manchester: Manchester University Press 1939), 24-32.

12 Hasan Malay, "New Inscriptions in the Denizli Museum", Arkeoloji Dergisi II (1994), 173-183.

13 Anthony R.R. Sheppard, "Inscriptions from Uşak, Denizli and Hisar Köy”, Anatolian Studies 31 (1981), 19-27.

14 Celal Şimşek. "Antik Dönemde Babadağ ve Çevresi”, I. Babadă̆ Sempozyumu Tarihte ve Günümüzde Babadağ Bildiri Metinleri (Denizli: Pamukkale Üniversitesi, 1999), 316-327; Celal Şimşek, "Attouda Nekropolü," 229-245.

15 Celal Şimşek ve Mehmet Okunak, “Attouda Seramikler,” II. Uluslararası Pişmiş Toprak Sempozyumu, 17-30 Haziran 2002 (Eskişehir: Eskişehir Tepebaşı Belediyesi, 2002), 83-93. 
nı arttırmak, uzun ve kısa vadeli hedeflerle koruma yaklaşımı doğrultusunda yeniden canlanmasını desteklemek üzerine odaklanılmıştır ${ }^{16} .2017$ yılında ise Haytoğlu tarafindan hatıra ve gözlemler kaleme alınmıştır. Bu çalışmada Hisar yerleşiminin tarihi, sosyolojik, sosyo-ekonomik, gelenek ve görenek özelliklerine değinilmiştir ${ }^{17}$. Şayın 2016 yılında yüksek lisans tezinde Hisar (Attouda) yerleşiminde bulunan mimarlık mirasının belgelenmesi, korunması ve sürdürülebilir kılınmasına yönelik öneriler getirmiştir $^{18}$. Bu bilgiler ise yerleşimin korunması ve yeniden canlandırılması gerekliliğini ortaya koymaktadır. Ancak bu konuda herhangi bir girişiminin günümüze kadar yapılmadığını söylemek mümkündür.

\section{Koruma Açısından GZFT Analizi}

Hisar (Attouda) yerleşiminin güçlü yönleri, kırsal dokusu ve doğal yapısının korunarak bugüne kadar gelmiş olması, güçlü ve tarihî kültürel mirasa sahip olmasıdır. Topoğrafik yapısı ve yerleşim etrafındaki ormanlık alanları ile şekillenen doğal peyzaj değerlerinin çekiciliğinin yerleşimin önemli özelliklerinden olduğu söylenebilir. Aynı zamanda yerel halkın arasında var olan birlik ve dayanışma bağlamında düzenli olarak yapılan geleneksel etkinliklerin günümüzde de sürdürülmesi ve halkın yerleşime geri dönme isteğinin olması yerleşimdeki hayatın devam ettirilmesinde güçlü bir etkendir. Hisar (Attouda) yerleşimi doğal ve kültürel özellikleri ile geçmişteki sosyal, kültürel, mimari, vb. özelliklerin anlaşılması ve günümüz değerleriyle bütünleşik olarak değerlendirilerek gelecek nesillere aktarılması için önemli bir kaynak niteliğindedir. Ancak alanın sit alanı özelliğinde olmasına rağmen fiziksel koruma çalışmalarının yapılmadı̆̆ı söylenebilir.

Arkeolojik ve kentsel sit alanı olan araştırma alanında koruma amaçlı planların hazırlanmaması ve halkın hem ekonomik şartlar hem de Hisar'1n sit alanı olmasından kaynaklı yerleşimi terk etmek zorunda kalması ve bu sebeple kullanılmayan yapıların harabeye dönüşmesi yerleşim için zayıflık göstergesidir. Aynı zamanda yerleşimin kullanılmaya devam edilmemesi ve koruma çalışmalarının yapılmaması kültür mirasının yok olmasına sebep olacaktır. Günümüzde hâlâ Hisar yerleşim dokusunun bütünlüğü bozulmamış olsa da birçok yapıda strüktürel problemler bulunmaktadır. Bunun yanı sıra, Hisar'ın antik dönemdeki konum özelliği, Afrodisias ile Hierapolis, Laodikeia ve Tripolis gibi önemli kentlerin etkileşim alanında ve bu arkeolojik alan-

16 Bilal Söğüt, "Denizli-Hisarköy Müze Deposundaki Mimari Bloklar,” Kültür Varlıklarl ve Müzeler Genel Müdürlügü 24. Araştırma Sonuçları Toplantısı 2 2006, haz. Dr. Fahriye Bayram ve Birnur Koral (Ankara: Kültür ve Turizm Bakanlığı Dösimm Basımevi 2007), 383-397; Bilal Söğüt, "Denizli'de Yaşayan Tarih Kenti Attouda (Hisarköyü)," Geçmişten Günümüze Denizli 37 (2013), 10-15; Bilal Söğüt, “Attouda (Hisar) Antik Kenti," Cedrus Akdeniz Uygarlıkları Araştırma Dergisi 5 (2017), 241-260.

17 Ercan Haytoğlu, Dağılan Köyün Hikayesi Attouda-Hisar (Denizli: Denizli Büyükşehir Belediyesi Kültür Yayınları, 2017), 128-135.

18 Gamze Şayın, "Denizli Hisarköy (Attuda) Kırsal Mimari Mirasının Doku Analizi ve Koruma Sorunları" (Yüksek lisans tezi, Dokuz Eylül Üniversitesi, 2016), 65. 
ların yurtiçi-yurtdışı turizm potansiyelinin olması, Babadağ'a olan yakınlığı ve ulaşım imkanlarının kolaylığı kültürel turizmin gelişmesine yönelik firsatlar sunmaktadır.

Somut ve somut olmayan miras değerleri, kent tarihi açısından önemli bir kaynak oluşturmaktadır. Halkın göç etmesinden kaynaklı yaşantının azalmaya başlamasından dolayı kırsal dokunun, doğal ve kültürel değerlerin zamanla yok olma tehlikesi Hisar (Attouda) yerleşimi için bir tehdit oluşturmaktadır. Niteliksiz ve harabe yapılar hem görünüm ve siluet açısından olumsuzluk yaratmakta hem de fiziksel yıkımların olma olasılı̆̆ını arttırmaktadır. GZFT (Güçlü yönler, Zayıf yönler, Fırsatlar, Tehditler) analizi (Tablo 1), çalışma alanının bir bütün olarak ele alınarak ve mevcut durumun incelenerek doğal ve kültürel değerlerinin ortaya konması ve korunmasına yönelik önerilerin oluşturulmasına katkı sağlamıştır. Bu bilgiler doğrultusunda korumaya yönelik resmî olarak başlamış olan koruma sürecinin uygulama düzeyinde gerçekleşmesi için girişimlerde bulunulmasının gerekliliği anlaşılmaktadır.

Tablo 1: Araştırma Alanının Koruma Açısından GZFT Analizi (Şimşek, 2019)

\begin{tabular}{|c|c|c|}
\hline & GÜÇLÜ YÖNLER & ZAYIF YÖNLER \\
\hline 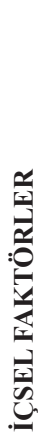 & $\begin{array}{ll}\checkmark & \text { Kırsal dokunun bozulmamış olması } \\
\checkmark & \text { Geleneksel mimari doku } \\
\checkmark & \text { Topoğrafik yapısı } \\
\checkmark & \text { Bitki varlığı } \\
\checkmark & \text { Hayvan varlığı } \\
\checkmark & \text { Etrafındaki ormanlık alanlar } \\
\checkmark & \text { Coğrafi konumu } \\
\checkmark & \text { Peyzajın çekiciliği (topoğrafik yapı, dağlar, } \\
& \text { ormanlık alanlar) } \\
\checkmark & \text { Köy halkının arasında var olan birlik ve } \\
& \text { dayanışma bağlamında düzenli olarak yapılan } \\
& \text { geleneksel etkinliklerin günümüzde de } \\
& \text { sürdürülmesi }\end{array}$ & $\begin{array}{ll}\checkmark & \text { Mekânsal ve işlevsel olarak bütüncül olarak ele } \\
& \text { alınan koruma amaçlı plan olmaması } \\
\checkmark & \text { Kültürel miras farkındalığının olmaması } \\
\checkmark & \text { Kültürel miras değerlerinin ulusal, bölgesel ve } \\
& \text { yerel tanıtım ve bilgilendirme çalışmalarının } \\
& \text { yeterli düzeyde olmaması } \\
\checkmark & \text { Halkın yerleşimi terk etmek zorunda kalması } \\
\checkmark & \text { Geleneksel konut yapılarında harabe yapılara } \\
& \text { rastlanması } \\
\checkmark & \text { Yerleşim içerisinde bazı alanlarda yaya } \\
& \text { dolaşımının zorluğu }\end{array}$ \\
\hline & FIRSATLAR & TEHDİTLER \\
\hline 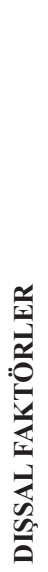 & 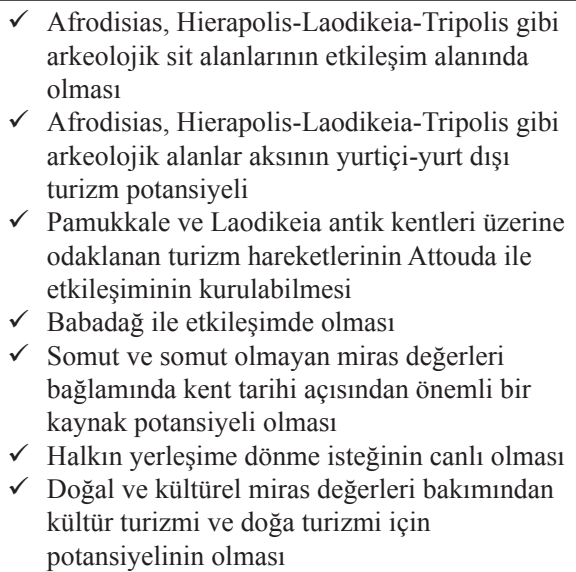 & $\begin{array}{l}\checkmark \text { Hisar kırsal yerleşimi dokusunun gün geçtikçe } \\
\text { yok olma tehlikesiyle karşı karşıya kalması } \\
\checkmark \text { Halkın yerleşimi terk etmesi, sosyal yaşantının } \\
\text { ve canlılığın kaybolması } \\
\checkmark \text { Sit alanı ilan edilmesine rağmen koruma amaçlı } \\
\text { çalışmalarda bulunulmaması } \\
\checkmark \text { Koruma kararları esas olmak üzere tarihsel } \\
\text { değerlerin gerek mevcut işlev gerekse yeni } \\
\text { işlevler verilmesi yoluyla korunması ve } \\
\text { yaşatılmasına yönelik yenileme projelerinin } \\
\text { yapılmış olmaması } \\
\checkmark \text { Niteliksiz ve harabe yapıların oluşturduğu } \\
\text { olumsuz görsel etki }\end{array}$ \\
\hline
\end{tabular}




\section{Öneriler}

Tarihî geçmişe sahip yerleşimler, bulundukları yerin fiziksel ve kültürel yapısını mekânlarına yansıtan özgün dokuya sahip alanlardır. Yaşatarak koruma yaklaşımı doğrultusunda kültürel mirasın turizme dâhil olma düşüncesi bu alanların korunması ve sürdürülebilirliğinin sağlanması açısından önemlidir. Tarihî yerleşimlerde hayatın devam etmesi, gelen ziyaretçilerin burayı kısa süreli de olsa deneyimleme firsatı bulmasını sağlamaktadır. Tarihî yerleşimlerin turizm açısından kullanımında korumakullanma dengesinin oluşturulması oldukça önemlidir. Bu alanlarda plansız yapılan çalışmalar ve taşıma kapasitesinin göz ardı edilmesi geri dönülmez zararlara sebep olmaktadır. Bu zararı en aza indirebilmek için koruma ve kullanmaya yönelik projelerin doğru bir planlama ile yapılması gerekmektedir.

Hisar (Attouda) yerleşimi doğal ve kültürel değerleri ile sosyal ve ekonomik yaşamından etkilenmiş, özgün mekânsal karakteristik özelliklere ve çok katmanlı yerleşim dokusuna sahip kültürel miras alanıdır.

Bu kapsamda araştırma alanın sürdürülebilirliği için bütünleşik koruma yaklaşımı temelinde koruma önerileri sunulmuştur (G. 2).

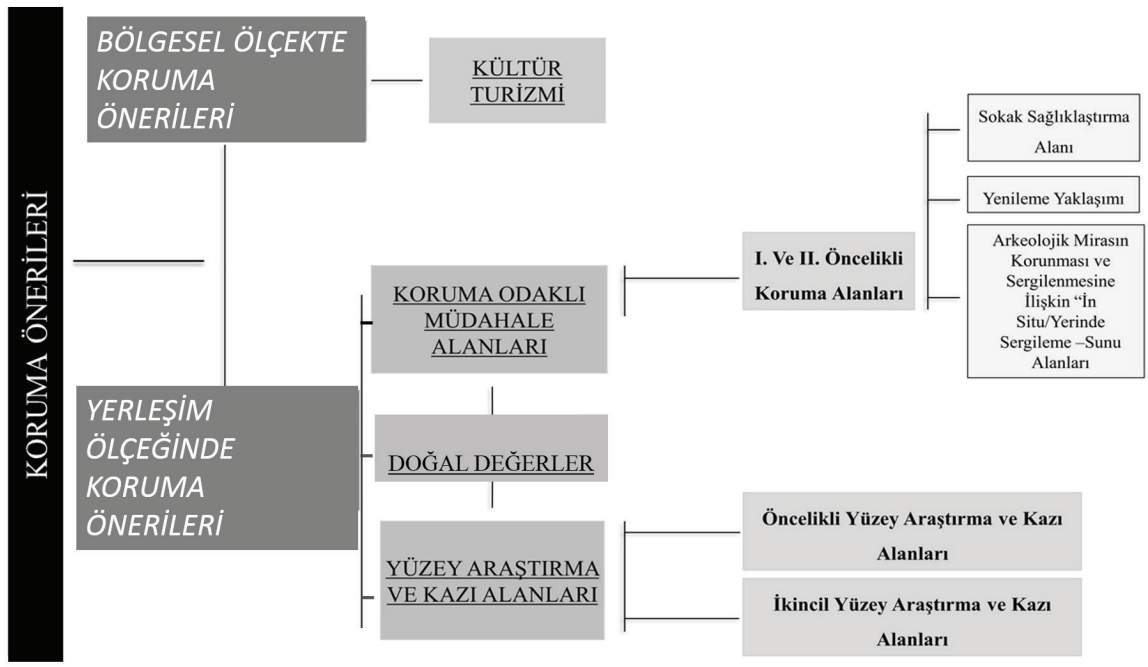

G. 2: Hisar (Attouda) Yerleşimi Koruma Önerileri (Şimşek, 2019)

\section{Bölgesel Ölçekte Koruma Önerileri}

Hisar (Attouda) yerleşimi, doğal ve kültürel miras değerlerine sahip olan ve Aphrodisias ile Laodikeia, Hierapolis ve Tripolis antik kentlerini birbirine bağlayan antik yol üzerinde yer alan, antik dönemde hem ticari hem de siyasi öneme sahip bir yerleşimdir. Bu kapsamda araştırma alanının ve bulunduğu bölgenin sahip olduğu doğal 
ve kültürel peyzaj özellikleri ve güzergâh boyunca öne çıkan tarihî ve sosyo-kültürel özellikteki yerleşimler ile olan yakınlıkları dikkate alınarak kültür rotası kullanımı öngörülmüştür. Bu vesileyle bu kültür rotası üzerinde bulunan Pamukkale ve Laodikeia antik kentleri üzerine odaklanan turizm hareketlerinin Attouda ile etkileşimi gerçekleşecektir. Afrodisias, Hierapolis-Laodikeia-Tripolis gibi arkeolojik alanlar aksının yurtiçi-yurt dışı turizm potansiyeli dikkate alındığında yerleşim alanının sahip olduğu doğal ve kültürel mirasın tanıtılması, kalkınmanın desteklenmesi ve mirasın korunması sağlanacaktır. Aphrodisias Antik kenti, Babadağ yerleşimi, Hisar (Attouda) yerleşimi, Trapezopolis Antik Kenti, Laodikeia Antik Kenti, Pamukkale-Hierapolis Antik Kenti, Karahayıt yerleşimi, Tripolis Antik Kenti, Buldan yerleşimi, Kibyra Antik Kenti (Gölhisar-Burdur) ile Antalya Lykia Bölgesindeki antik kentleri ve tarihî yerleşimleri kapsayan kültür rotasının kullanılması önerilmektedir.

Bununla birlikte, Aphrodisias, Trapezopolis, Hisar (Attouda), Laodikeia, Hierapolis, Tripolis gibi antik kentlerin rotasında yer alan ve turizm merkezleri ile etkileşimi için altyapı ve mekân niteliğinin artırılması, belirlenen rotada acil müdahale gereken alanlarda iyileştirmeler yapılması, rotanın bir ögesi olarak görülen doğal, tarihî ve kültürel alanların ve yapıların korunarak geliştirilmesi, görünürlüğünün ve erişilebilirliğinin artıılması, yapıların kültür turizmi kapsamında uygun işlevler kazandırılarak yeniden kullanılarak yaşatılması için ilgili kamu, kurum ve kuruluşlar tarafından planlama-uygulama çalışmaları yapılması gerekmektedir.

\section{Yerleşim Ölçeğinde Koruma Önerileri}

Araştırma alanında yerleşim ölçeğinde koruma önerileri için belirlenen bölgeleme sınırlarında coğrafi yapı, parsel kullanımları, yapı yoğunluğu, yapıların tescil durumu ve fiziki durumları, yüzey araştırma ve kazı alanlarının sınırlarının belirlenmesinde kalıntıların yeri, korunma-kullanma durumu ve mimari özellikler ve araştırma alanında çalışma gerçekleştiren bilim insanlarının görüşleri etkili olmuştur. Kentsel ve arkeolojik sit alanı özelliğinde olan araştırma alanı, (a) kültürel değerler bağlamında koruma odaklı müdahale alanları konusunda öneriler, (b) doğal değerler konusunda öneriler, (c) yüzey araştırmaları ve kazı alanları için koruma önerileri olmak üzere üç başlıkta ele alınmıştır (G. 3). 


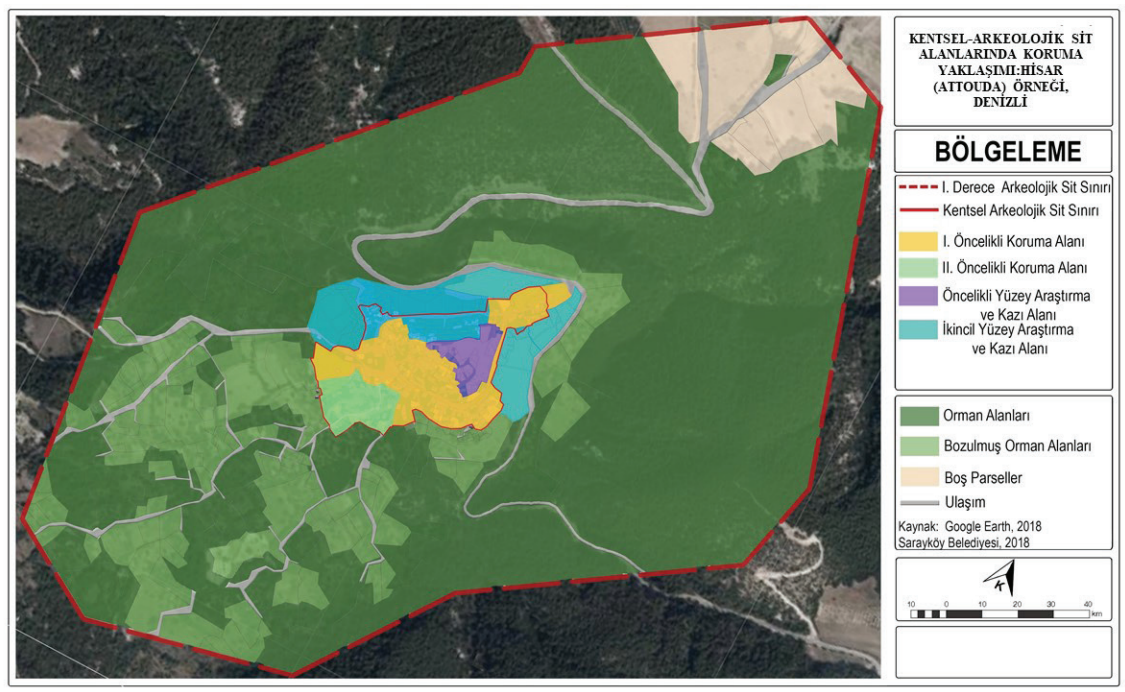

G. 3: Bölgeleme Paftası (Şimşek, 2019)

\section{a. Kültürel Değerler Bağlamında Koruma Odaklı Müdahale Alanları İçin Öneriler}

Koruma odaklı müdahale alanları, parsel kullanımları, yapı yoğunluğu, yapıların tescil durumu ve fiziki durumları açısından değerlendirilerek I. ve II. öncelikli derecede koruma alanları olarak ayrılmıştır. I. öncelikli koruma alanı yerleşimin güney kısmında yer alan, Sarayköy'den gelen yolun Hisar Camisi'nin bulunduğu meydanda birleşerek oluşturduğu bölge ve yerleşimin güney batı kısmını kapsayan alandır. $\mathrm{Bu}$ alan, tescilli ve fiziki durumu iyi olan yapıların yoğun olduğu, yerleşimin meydan kısmını ve bu bölgedeki konut dışındaki kullanımları olan resmi yapıları, ticaret yapılarını ve yerleşimin giriş bölgesini içeren alan olarak koruma çalışmalarının öncelikli olarak bu bölgede başlayabileceği önerisi getirilen bölgedir. Bu alanlarda restorasyon ilkelerine bağlı kalarak, ilgili kurum ve araştırma alanında çalışma gerçekleştiren bilim insanlarının görüşleri ile yasalar doğrultusunda yapılar özgün konumlarında, olabildiğince özgün işleviyle korunarak kullanılmalıdır. II. öncelikli koruma alanında harabe durumunda ve yıkılma tehlikesi olan ya da tek duvarı ayakta kalmış yapılar bulunmaktadır. Bu bölgede antik döneme ait buluntu olma olas1lığ $1^{19}$ öngörülmektedir. Bu nedenle buradaki yapıların süreç içerisinde ilgili kurum kararları ve araştırma alanında çalışma gerçekleştiren bilim insanlarının görüşleri doğrultusunda ikincil yüzey araştırma ve kazı alanı olarak önerilen alanlara dahil edilmesi üzerinde durulmaktadır. $\mathrm{Bu}$ öneriler doğrultusunda I. ve II. öncelikli koruma alanları; sokak sağglılaştırma alant, yenileme alanlart, arkeolojik mirası korunması ve yerinde sergilenmesine yönelik yerinde-in situ sergileme-sunu alanları olarak üç başlık altında ele alınmiştır.

19 Araştırma alanı ile ilgili çalışmaları olan bilim insanı görüşü, B. Söğüt (2019). 
Sokak sağlıklaştırma alanı: Sokak sağlıklaştırma alanı, kentsel sit alanı içerisinde yer alan yerleşime ana yoldan gelerek yerleşimdeki Hisar Camisi'nin olduğu ve geleneksel kullanımda meydan olarak kullanılan alana ulaşan yol ile tescilli mimarlık örneklerinin de bulunduğu sokaklardır. Tarihî doku parçalarının korunması ve yaşatılarak kullanılabilmesi için sokakların ve meydanın altyapı, zemin düzenleme ve yapıların cephe sağlıklaştırma çalışmaları yürütülmelidir.

Alanın Sarayköy tarafındaki (kuzey-doğu) girişinde yer alan ve önceden meydan olduğu düşünülen ${ }^{20}$ alan yeniden kullanımda ziyaretçileri karşılama alanı olarak işlev görmesi önerilmektedir. Yerleşimin büyüklü̆̆̈u ve taşıma kapasitesi göz önünde bulundurularak sadece yaya dolaşımının sağlanması için, park yeri çözümlemeleri ile araçların alana girişinin önlenmesi düşünülmüştür. Bunun için yerleşimi çevreleyen ana yolun üst bölümünün kullanımı kaldırılarak sadece yerleşimin ortasından geçen ve Hisar Camisi'nin olduğu meydana ulaşan yolun araç kullanımına uygun olarak yenilmesine ve sadece acil durumlar için araçların kullanımına açılmasına yönelik koruma esasları çerçevesinde peyzaj tasarım projesinin hazırlanarak uygulanması uygun olacaktır. Yerleşimin kuzey-doğu girişindeki bölgede türbe ve tescilli-tescilsiz sivil mimari yapılar bulunmaktadır. Özellikle sit alanı ilan edilmeden önce evlerini kullanan kişilerin, özgün dokuyu dikkate almadan yapmış oldukları konut cephelerindeki tadilatların iyileştirme çalışmalarının yapılması gerekmektedir. Dokuya uyumsuz yapıların cephe sağıklaştırmaları yapılarak konut olarak kullanımlarına devam etmeleri, sokak sağlıklaştırma alanında ve meydan alanında koruma esasları çerçevesinde peyzaj tasarım projesi oluşturularak uygulanması ve türbenin cephe sağlıklaştırması ve çevre düzenlemesi yapılarak ziyarete açılması önerilmektedir. Sağlıklaştırma alanı içerisindeki sokakların zeminleri asfalt ve doğal taş niteliğindedir. Özgün taş döşeme dokusuna kavuşturmak amacıyla asfalt yollar taş döşemesi ile değiştirilmelidir. Bununla birlikte doğal taş döşeli yollar zamanla toprak örtüsü ve otsu bitkilerden kullanılamamaktadır. Bu yolların iyileştirmeye yönelik peyzaj çalışmalarının yapılması gerekmektedir. Bu kapsamda mevcuttaki alan içerisinde sokakları kaplayan otsu bitkilerin temizlenmesi ve geçişlere engel olan çalıların düzenli olarak budanarak belirli bir formda kalması sağlanmalıdır. Böyle bir düzenleme hem kullanım hem de görsel açıdan işlevsel olacaktır.

Yenileme alanları: I. ve II. öncelikli koruma alanları içerisinde bulunan tarihi ve taşınmaz kültür varlıkları, yapı niteliği kötü ya da harabe durumundaki yapıların koruma kurulu kararları doğrultusunda rölöve, restitüsyon, restorasyon projelerine göre yeniden inşa edilmelidir. Canlandırma - yaşatarak koruma yaklaşımı doğrultusunda, mülk sahiplerine yapıların bakım ve onarım desteğinin ve teknik yardımların sağlanması önem arz etmektedir. Halkın da bu konuda bilinçlendirilmesi sağlanarak, evleri yaşatmak ve gelecek nesillere aktarmak mümkün olacaktır.

20 Araştırma alanı ile ilgili çalışmaları olan bilim insanı görüşü, B. Söğüt (2019). 
Kültür turizmi kapsamında koruma odaklı alanların günübirlik kullanıma teşvik amaçlı olarak önerilen sokak sağlıklaştırma güzergahı üzerindeki yapıların önceki kullanımları temel alınarak yeniden işlevlendirilmesi ile birlikte rölöve, restitüsyon ve restorasyon önerileri G. 4 ve Tablo 2'de verilmiştir. Yeniden işlevlendirilerek aktif hâle getirilen ticari yapıların işletilmesinde öncelik yerel halka tanınmalı ve çeşitli kurumlarca maddi destek sağlanmalıdır. Böylelikle hem kullanılan yapılarda düzenli bakım ve onarım çalışmaları yapılarak yaşatılan kentsel dokunun özgünlüğünü kaybetmemesi hem de yerleşimde yaşamını devam ettirmek isteyen halka olanak sağlanacaktır. Bu kapsamda yapılara önerilen işlevler; geleneksel yaşamın ve yerleşimin tarihi birikiminin sergileneceği müze, dokuma atölyesi, yerleşimdeki yöresel ürünlerin sunulacağı tadım evi, alan hakkında bilgi verileceği tanıtım merkezi ve mevcut konut kullanımlarının devam etmesi şeklindedir.

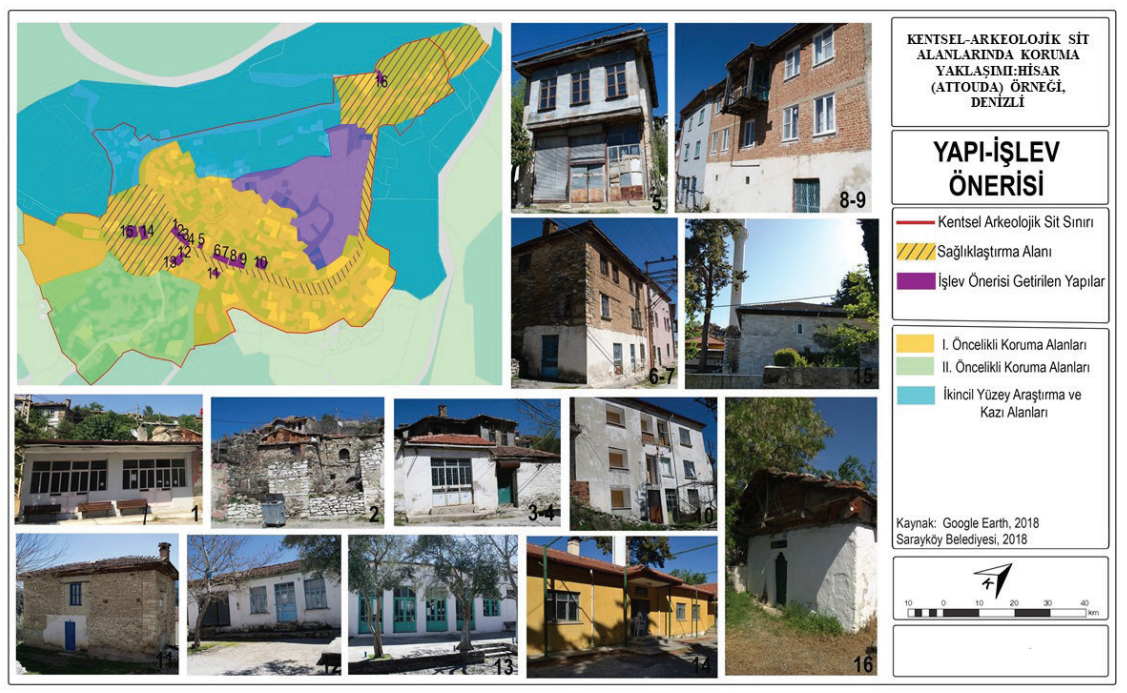

G. 4. Hisar (Attouda) Yerleşiminde Sokak Sağlıklaştırma Alanında Yapılara Verilen Yeni İşlev ve Yeniden İnşa Önerileri Paftası (Şimşek, 2019) 
Tablo 2: Sokak Sağlıklaştırma Alanındaki Yapılara Getirilen İşlev ve Yeniden İnşa Önerileri (Şimşek, 2019)

\begin{tabular}{|c|c|}
\hline Konut & İşlev Önerileri \\
\hline 1 & $\begin{array}{l}\text { Kahvehane olarak kullanılmış ve bugün de işlevini devam ettiren yapının restorasyon } \\
\text { ilkeleri doğrultusunda dokuya uyumlu olarak cephe sağlıklaştırılması yapılması } \\
\text { önerilmektedir. }\end{array}$ \\
\hline 2 & $\begin{array}{l}\text { Bugün kullanım dışı kalan, harabe durumdaki tescilli yapının yenileme çalışmalarına dahil } \\
\text { edilerek, yeniden işlevdirilmesi ve geleneksel konut yapısının gelen ziyaretçilere sunulması } \\
\text { önerilmektedir. }\end{array}$ \\
\hline $3-4$ & $\begin{array}{l}\text { Market olarak kullanılmış ancak bugün kullanım dışı olan tescilsiz } 3 \text { nolu yapının yanındaki } \\
\text { tescilli yapı ile birlikte düşünülerek gelen ziyaretçilerin yerleşim alanını gezerken temel } \\
\text { ihtiyaçlarını karşılayabileceği küçük market olarak kullanımı önerilmektedir. }\end{array}$ \\
\hline 5 & $\begin{array}{l}\text { Üst katı yaşam alanı ve alt katı ticaret alanı olarak kullanılmış ancak bugün kullanım dışı } \\
\text { olan tescilli yapının restorasyon ilkeleri dikkate alınmadan dokuya uyumsuz olarak cephe } \\
\text { tadilatı yapılmıştır. Bu yapının kurallar çerçevesinde restorasyon çalışmaları yapılarak } \\
\text { dokuma atölyesi olarak kullanımı önerilmektedir. }\end{array}$ \\
\hline $6-7-8-9-11$ & $\begin{array}{l}\text { Konut olarak kullanımı devam ettirilen yapıların cephe sağlıklaştırma yapılarak mevcut } \\
\text { işlevine devam etmesi önerilmektedir. }\end{array}$ \\
\hline 10 & $\begin{array}{l}\text { Konut olarak kullanılmış, bugün kullanım dışı olan tescilli yapının restorasyon ilkeleri göz } \\
\text { ardı edilerek yapılmış düzenlemelerin sökülerek dokuya uyumlu hale getirilerek mevcut } \\
\text { işlevine devam etmesi önerilmektedir. }\end{array}$ \\
\hline 12 & $\begin{array}{l}\text { Bugün kullanım dışı olan yapının restore edilerek ziyaretçilerin alana ilişkin bilgi alabileceği } \\
\text { tanıtım merkezi olarak kullanımı önerilmektedir. }\end{array}$ \\
\hline 13 & $\begin{array}{l}\text { Kahvehane olarak kullanımını sürdüren yapının iç ve dış bölümleri restore edilerek yöresel } \\
\text { yemek tadım evi olarak kullanımı önerilmektedir. }\end{array}$ \\
\hline 14 & $\begin{array}{l}\text { İlkokul olarak kullanılmış ancak bugün kullanım dışı olan yapının bahçesiyle birlikte müze } \\
\text { olarak kullanımı önerilmektedir. Hisar Camii yanında sergilenen antik döneme ait taşınabilir } \\
\text { eserlerin bahçede koruma altına alınarak sergilenmesi önerilmektedir. }\end{array}$ \\
\hline 15 & $\begin{array}{l}\text { Anıtsal yapı olarak Hisar Camii’nin mevcut kullanımı devam ettirilerek, bakımlarının } \\
\text { düzenli olarak yapılması ve camii etrafındaki duvarın yenilenmesi önerilmektedir. }\end{array}$ \\
\hline 16 & $\begin{array}{l}\text { Anıtsal yapı olarak Türbe’nin korunarak ziyarete açılması için restorasyon işlemlerinin } \\
\text { yapılarak çevresinin peyzaj tasarım-uygulama çalışmalarının yapılması önerilmektedir. }\end{array}$ \\
\hline
\end{tabular}

Arkeolojik mirasın korunmast ve sergilenmesine ilişkin yerinde-in situ sergilemesunu alanlart: Mevcut durumda Hisar Cami avlusunda sergilenen taşınabilir arkeolojik kalıntıların, sokak sağlıklaştırma kapsamında müze olarak değerlendirilebileceği düşünülen okulun bahçesine taşınması önerilmektedir. Bunun için tescilsiz yapının özgün dokuya uyumlu olarak cephe sağlıklaştırmasının yapılması ve çevresinin peyzaj tasarım projesinin hazırlanması uygun olacaktır. Bu kapsamda taşınabilir kültür varlıklarının dış mekânda doğal koşullardan tahrip olmasını önlemek ve olumsuz kültürel etkilerden korumak amacıyla koruma altına alınması gerekmektedir. Taşınabilir kültür varlıklarının sergilenmesinde çevre koşullarından korunması amacıyla yapılacak üst örtülerin formu ve malzemesi geleneksel dokuya uyumlu seçilmelidir. Korumada şeffaf yüzeyler kullanılmalı, örtüler dış etkilerden koruduğu tarihi buluntuları vurgulayacak ve gerektiğinde sökülebilecek özellikte olmalıdır. Yüzey araştırmaları ve kazı alanlarında bulunan ve sonraki süreçte kazı çalışmaları sonucunda ortaya çıkarılacak olan taşınmaz kültür varlıklarının dış etkilerden etkilenmeden ve korunarak yerinde-in-situ olarak sergilenebilmesi için sade strüktürlü üst örtülerin kullanılması önerilmektedir. 


\section{b. Doğal Değerler Konusunda Öneriler}

Hisar (Attouda) yerleşimi mevcut dokusunu sadece kültürel özellikleriyle değil doğal özellikleriyle de korumuştur. Denizli Babadağ, Merkezefendi ve Tavas İlçeleri sınırları içerisinde yer alan Salbakos Dağı ve çevresi 08/04/2019 tarihli 82919 sayılı olur ile "Doğal Sit-Nitelikli Doğal Koruma Alanı" olarak tescil edilmiştir. Araştırma alanı antik dönemde Phrygia ile Karia bölgelerinin sınırını oluşturan Salbakos Dağı'nın kuzeyinde, doğu yamacında yer almaktadır. Doğal Sit Alanları Koruma ve Kullanma Koşulları İlke Kararı doğrultusunda Sürdürülebilir Koruma ve Kontrollü Kullanım Alanları kapsamında, araştırma alanın yakınlığı ve çevresindeki tabiat varlığı ile tarihî yerleşim alanının sahip olduğu doğal ve kültürel değerleri nedeniyle koruma çalışmalarının bu bölgede devam ederek araştırma alanı ve çevresindeki orman dokusunun korunması gerekmektedir.

Kültür ve Turizm Bakanlığı 27/10/2006 tarihli 26329 sayılı ilke kararına göre kentsel sit alanları, bulunduğu çevre ve bitki örtüleri, bahçeleri ile birlikte korunmalıdır. Kentsel arkeolojik sit alanı olan Hisar (Attouda) yerleşimi içerisindeki yeşil dokunun ve çevresindeki orman ve tarım alanlarından orman alanlarına dönüşen doğal peyzajın mevcut hâliyle mimari değerleri ile birlikte bir bütün olarak koruma planlarına dâhil edilmesi gerekmektedir. Tabiatı ve Biyolojik Çeşitliliği Koruma Kanunu Tasarısı ile Çevre Komisyonu Raporu (2012) Madde 7'de belirtildiği üzere korumaya yönelik hazırlanmış planlar, birçok kamu kurum ve kuruluşların ortak görüşü ile uygulanmalıdır. Yapılacak her ölçekteki planların, yerel, bölgesel ve ulusal ölçekteki planlarla desteklenmesi gerekmektedir. Ayrıca koruma alanlarının gerçek sahipleri olan yöre halkının talepleri doğrultusunda planlama çalışmalarının yapılması ve ilgili tüm tarafların katılımını sağlayacak düzenlemeler getirilmesi önemlidir.

Topoğrafik yapısı açısından eğimin az olduğu güney yamaca kurulu olan Hisar'da yöresel, özgün mimari ile birlikte yerleşimdeki yeşil doku, yerleşim etrafindaki vadiler, dağlık alanlar ve orman örtüsü ile özellikle mevsim değişimlerinde bitki örtüsünün yarattığı alg1, desen, biçim, renk ve doku çeşitliliği, dağlk alanları sınırlayan yol öğeleri görsel kaliteyi arttırmakta, peyzaja çarpıcı ve ilginç ayrıntılar katmaktadır. Hisar (Attouda) hem yerleşimi alanı hem de çevresinde sahip olduğu doğal değerleri bakımından kültür turizmi ve doğa turizmine olanak sağlamaktadır.

\section{c. Yüzey Araştırmaları ve Kazı Alanları İçin Koruma Önerileri}

Arkeolojik sit özelliğindeki araştırma alanında henüz bir yüzey araştırması ve kazı çalışması olmamasından dolayı alana getirilecek önerilerde 658 nolu ilke kararına göre koruma ve kullanma koşulları dikkate alınmıştır. Araştırma alanında yüzey araştırma ve kazı çalışmalarının etkin olarak yapılabilmesi için öncelikli olarak yüzey araştırması ve kazı yapılabilecek alanlar belirlenerek bölgeleme sınırları oluşturul- 
muştur. Yüzey araştırma ve kazı alanlarının bölgeleme sınırının belirlenmesinde, alanın doğal yapısı (topoğrafik yapı, bakı, eğim), antik döneme ait kentsel yerleşim alanının ve nekropol alanının yeri, yerleşim içerisindeki kalıntılar, doğal yapılardaki izler (örneğin, kayalar) dikkate alınmıştır. Bu doğrultuda yüzey araştırma ve kazı alanları öncelikli yüzey araştırması ve kazı alanı ve ikincil yüzey araştırma ve kazı alanı olmak üzere iki bölgeleme alanı olarak değerlendirilmiştir (G. 5).

Yüzey araştırma ve kazı alanında ve kentsel sit alanında yapılacak her türlü çalışmanın koruma ilkeleri temelinde, yasal çerçeve sınırları içerisinde yapılması gerekmektedir. Kentsel sit sınırı içerisindeki kazı çalışmalarının ve sonrasında arkeolojik buluntuların korunması ve sergilenmesi ile kentsel sit içerisindeki restorasyon, yenileme ve sağlıklaştırma çalışmaları birlikte planlanarak uygulanmalıdır. Gerek geleneksel mimari doku koruma çalışmaları gerekse kazı çalışmaları birbirini etkilemeden ancak birbiriyle etkileşimde olacak şekilde planlanmalı ve sahip olduğu kültürel mirasın ve yerleşim dokusunun korunması ve sürdürülebilirliği yaklaşımı benimsenmelidir. Kazı çalışmaları sonrasında ortaya çıkan taşınmaz kültür varlıkları yerinde-in situ olarak korunmalı, taşınabilir kültür varlıkları ise uygun görülen müze içinde ya da çevresinde sergilenerek korunmalıdır.

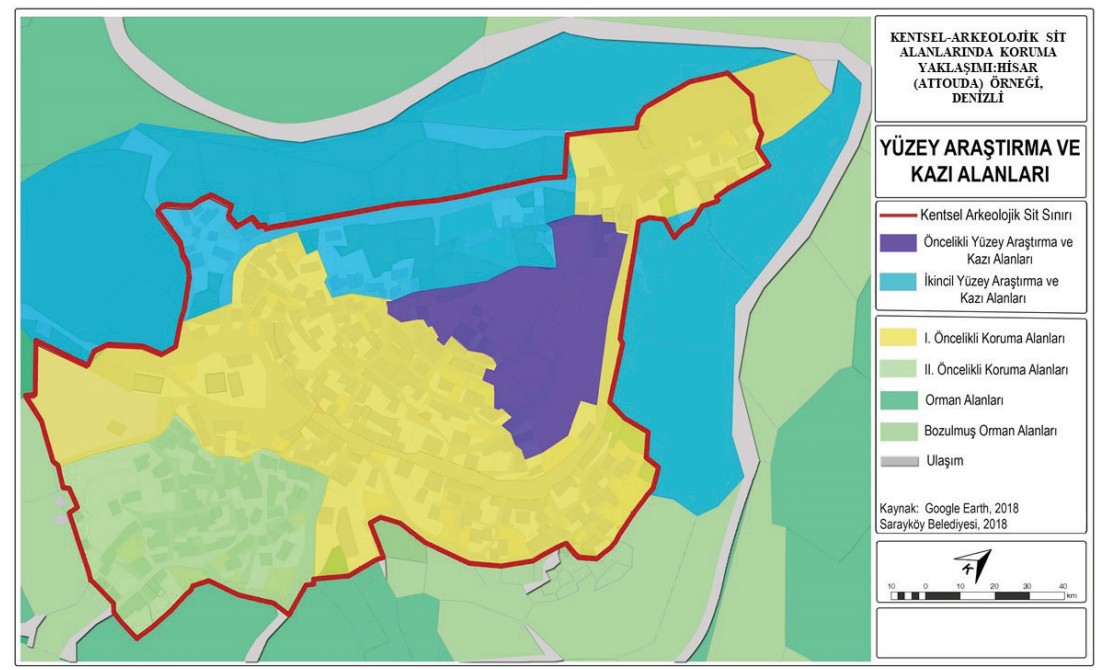

G. 5. Araştırma Alanında Öngörülen Yüzey Araştırma ve Kazı Alanları (Şimşek, 2019)

\section{Sonuç}

Helenistik ve Roma Dönemi’nin izlerini taşıyan antik kentin üzerine Osmanlı Dönemi'nde Hisar yerleşimi kurulmuş ve yerleşim alanı özgün dokusunu koruyarak bugüne kadar gelmiştir. Koruma kurulları tarafından I. derece arkeolojik sit ve kentsel sit alanı olarak tescillenen yerleşimde ${ }^{21}$ bugüne kadar gerekli koruma çalışmaları ya-

21 Hisar (Attouda) yerleşimi Kültür Varlıklarını Koruma Bölge Kurulu tarafından 1988'de I. derece arkeolojik sit alanı ve 2013'te kentsel arkeolojik sit alanı olarak belirlenmiştir. 
pılmamıştır. Oysaki tarihî geçmişi ve kültürel altyapısı ile Hisar (Attouda) yerleşimi, bulunduğu bölge içinde kültürel miras karakteristiklerini günümüze aktarabilmelidir. Bu nedenle yerleşimin doğal ve kültürel değerleri ile oluşan özgünlüğünü günümüz ihtiyaçları doğrultusunda yeniden yorumlamak, bulunduğumuz dönemin kimliğini koruyarak geleceğe aktarılması açısından önem arz etmektedir.

Bu kapsamda geçmişten bugüne ulaşmış, tarihsel süreklilikte değişip dönüşerek şekillenen, Hisar (Attouda) kültürel miras alanının tarihî geçmiş ile bugün birlikteliğinin yaşatılması, korunması ve gelecek kuşaklara aktarılması için bu araştırma ile bütünleşik koruma yaklaşımı temelinde ortaya konulan koruma önerilerinin planlama, tasarlama ve uygulama süreçlerine katkı sağlayacağı düşünülmektedir.

Hakem Değerlendirmesi: Dış bağımsız.

Çıkar Çatışması: Yazarlar çıkar çatışması bildirmemiştir.

Finansal Destek: Bu araştırma, Pamukkale Üniversitesi Bilimsel Araştırma Projeleri Koordinasyon Birimi (2018FEBE069) tarafından finansal olarak desteklenmiştir.

Peer-review: Externally peer-reviewed.

Conflict of Interest: The authors have no conflict of interest to declare.

Grant Support: This research was financially supported by Pamukkale University Scientific Research Projects Coordination Unit (2018FEBE069).

\section{Kaynakça/References}

Anderson, John George Clark. “A Summer in Phrygia:1.” The Journal of Hellenic Studies 18 (1898): 398-400.

Buckler, William Hepburn ve William Moir Calder. Monuments and Documents from Phrygia and Caria. Manchester: Manchester University Press, 1939.

Çelik, Ali, Mehmet Çiçek ve Muhammet Uşak. "Denizli İli ve Çevresinde Yayılış Gösteren Bazı Türlerin Etnobotanik Özellikleri.” I. Babadağ Sempozyumu Tarihte ve Günümüzde Babadă̆ Bildiri Metinleri, Denizli: Pamukkale Üniversitesi, 1999, 136-153.

“Kırsal Kalkınma Özel İhtisas Komisyonu Raporu, Sekizinci Beş Yıllık Kalkınma Planı.” Devlet Planlama Teşkilatı. Ankara, 2000, 26-27. Erişim 13 Mart 2019.

https://sbb.gov.tr/wp-content/uploads/2018/11/08_KirsalKalkinma.pdf.

Eminağaoğlu, Zehra ve Sonay Çevik. "Kırsal Yerleşmelere İlişkin Tasarım Politikaları ve Araçlar." Gazi Üniversitesi Mühendislik Mimarlık Fakültesi Dergisi 22/1 (2007): 157-162.

Erdoğan, Elmas. "Perge Arkeolojik Sit Alanı, Peyzaj Özellikleri ve Koruma Sorunları.” Bartın Orman Fakültesi Dergisi 8/10 (2006): 36-47.

Gez, Sefa ve Solmaz Şimşek. "Babadağ'ın Tıbbi Bitkileri.” I. Babadă̆ Sempozyumu Tarihte ve Günümüzde Babadağ Bildiri Metinleri. Denizli: Pamukkale Üniversitesi, 1999, 128-135.

Haytoğlu, Ercan. Dă̆ılan Köyün Hikayesi Attouda-Hisar. Denizli: Denizli Büyükşehir Belediyesi Kültür Yayınları, 2017.

Malay, Hasan. "New Inscriptions in the Denizli Museum.” Arkeoloji Dergisi II (1994): 173-183. 
Özcan, Koray ve M. Serhat Yenice. “Arkeolojik Mirasın Sürdürülebilirliği: Koruma-Geliştirme Stratejileri İçin Bir Yöntem Önerisi.” Uluslararası İnsan Bilimleri Dergisi 5/1 (2008): 1-16.

Ramsay, William Mitchell. The Historical Geography of Asia Minor. (London: Cambridge University Press, 1890).

Sheppard, Anthony R. R. "Inscriptions from Uşak, Denizli and Hisar Köy.” Anatolian Studies 31 (1981): 19-27.

Söğüt, Bilal. "Denizli-Hisarköy Müze Deposundaki Mimari Bloklar.” Kültür Varlıkları ve Müzeler Genel Müdürlüğ̈̈ 24. Araştırma Sonuçları Toplantısı 2, Çanakkale 29 Mayıs-2 Haziran 2006. Haz. Dr. Fahriye Bayram ve Birnur Koral (Ankara: Kültür ve Turizm Bakanlığı Dösimm Basımevi 2007), 383-397.

Söğüt, Bilal. "Denizli’de Yaşayan Tarih Kenti Attouda (Hisarköyü)." Geçmişten Günümüze Denizli 37 (2013): 10-15.

Söğüt, Bilal. “Attouda (Hisar) Antik Kenti." Cedrus Akdeniz Uygarlıkları Araştırma Dergisi 5 (2017): 241-260.

Şayın, Gamze. "Denizli Hisarköy (Attuda) Kırsal Mimari Mirasının Doku Analizi ve Koruma Sorunları.” Yüksek lisans tezi, Dokuz Eylül Üniversitesi, 2016.

Şimşek, Celal. “Antik Dönemde Babadağ ve Çevresi,” I. Babadă̆ Sempozyumu Tarihte ve Günümüzde Babadă̆ Bildiri Metinleri. Denizli: Pamukkale Üniversitesi, 1999, 316-327.

Şimşek, Celal. “Attouda Nekropolü”. Birinci Uluslararası Aşağı Büyük Menderes Havzası Tarih, Arkeoloji ve Sanat Tarihi Sempozyumu, Söke, 15-16 Kasım 2001. Ed. Adil Adnan Öztürk. Aydın: Adnan Menderes Üniversitesi, 2002, 229-245.

Şimşek, Celal ve Mehmet Okunak. "Attouda Seramikler." II. Uluslararası Pişmişs Toprak Sempozyumu, Eskişehir, 17-30 Haziran 2002. Eskişehir: Eskişehir Tepebaşı Belediyesi, 2002, 83-93.

Şimşek, İlcan. "Kentsel Arkeolojik Sit Alanlarında Koruma-Canlandırma Önerileri: Hisar (Attouda) Örneği." Yüksek lisans tezi, Pamukkale Üniversitesi, 2019.

Urhan, Raşit, Mehmet Doğaç, Ali Zeytünoğlu ve Yakup Kaska. "Babadağ (Denizli) İlçesinin Memeli Hayvanlar1.” I. Babadă̆ Sempozyumu Tarihte ve Günümüzde Babadă̆ Bildiri Metinleri, Denizli: Pamukkale Üniversitesi, 1999, 179-180. 